\title{
Tobacco use and the relationship with HIV risk behaviors in Puerto Rico residents of 18 years and over - A cross-sectional study
}

\author{
Alex Cabrera-Serrano, Marcos E. Felici-Giovanini, Miriam V. Ramos-Colón, Antonio L. \\ Cases-Rosario, Abraham Rivera-Alvarado \\ Department of Health, San Juan, Puerto Rico
}

Correspondence: Alex Cabrera-Serrano. Address: Puerto Rico Department of Health, Tobacco Control and Oral Health Division, PO Box 70184, San Juan, PR 00936. Email: alecabrera@salud.gov.

Received: November 20, 2012

Accepted: December 18, 2012

Online Published: January 23, 2013

DOI : $10.5430 /$ jnep.v3n8p75

URL: http://dx.doi.org/10.5430/jnep.v3n8p75

\section{Abstract}

Background: Currently there is no country, social class, or group of people worldwide that has not been affected by HIV/AIDS. The HIV epidemic has been surrounded by great secrecy and ignorance that has fostered the spread of the virus. HIV/AIDS and tobacco use represent the only two major causes of death worldwide. Likewise, tobacco use is a leading cause of morbidity and mortality in people without HIV and is highly prevalent in HIV positive population. The main objective of this research is to provide an epidemiological profile of people who reported having an HIV test in their lifetime and smoke (PHHT-S) in Puerto Rico. Our secondary objectives are: 1) identify the existence of statistically significant differences between PHHT-S vs. people who have had an HIV test in their lifetime and do not smoke (PHHT-NS), and 2) determine the risk of having been in a risk situation for HIV infection among PHHT-S vs. PHHT-NS.

Methods: Through a cross-sectional study methodology the analysis of 2010 database of the Puerto Rico Behavioral Risk Factor Surveillance System (PRBRFSS) was performed with the Statistical Package for the Social Sciences (SPSS). In the first part, a univariate analysis was performed using frequency distributions and percentages for categorical variables and means and standard deviation calculation for continuous variables. In the second part through a bivariate analysis, smokers and non-smokers who have had an HIV test in their lifetime were compared using chi-square tests, Odds Ratio and 95\% confidence intervals (CI).

Results: Among the 43.2\% $(1,009,587)$ of the Puerto Ricans of 18 years and over who reported having an HIV test in their lifetime, $16.6 \%(167,242)$ reported being smokers. This study provides statistically significant data to support the existence of differences between PHHT-S and PHHT-NS, especially in the area of risk behaviors related to HIV. PHHT-S are 2.24 times more likely to engage in some risky behavior that can lead them become infected with HIV in comparison with the PHHT-NS.

Conclusions: This study provides strong evidence that confirm the need for collaboration between the Tobacco Control Programs and HIV programs to implement new strategies to promote a greater number of people who smoke get tested for HIV and to influence public policy and systems change.

\section{Key words}

HIV, HIV test, HIV/AIDS, Risk behaviors, Tobacco use, Smoking, Puerto Ricans, Hispanics, HIV and tobacco use 


\section{Introduction}

Since the beginning of the HIV epidemic in the eighties, this condition has been one of the biggest challenges for the medicine and to the public health field. Currently there is no country, social class, or group of people worldwide that has not been affected by this condition. The HIV epidemic has been surrounded by great secrecy and ignorance that has fostered the spread of the virus. The number of people living with HIV worldwide rose in 20\% between 2001 and $2009^{[1]}$. In the USA, more than one million of people living with HIV and approximately $25 \%$ are unaware that they are infected ${ }^{[2]}$. A piece of research in 2007, which included 37 states and territories, one of these being Puerto Rico, estimated that 41,611 people received an HIV diagnosis, and of these $20.2 \%$ were Hispanic/Latinos ${ }^{[3]}$. This research also demonstrate that among Hispanics/Latinos in Puerto Rico the estimated life time risk (ELR) was 2.08\%, whereas in the 37 states was $1.90 \%{ }^{[3]}$. From 1981 to February 2011, a total of 34,040 cases, have been reported to the surveillance system of HIV/AIDS in Puerto Rico. By 2008, the system had identified 572 people with HIV in Puerto Rico, while 363 people were diagnosed with AIDS.

In terms of tobacco use, the prevalence in Puerto Rico for 2010 was $11.9 \%$ among people of 18 years and over ${ }^{[4]}$. Currently there is a growing recognition that this practice increases the risk of infection with sexually transmitted diseases ${ }^{[5-7]}$. Multiple researches have shown that tobacco use alters the lung function and reduces the individual's ability to fight serious infections and also weaken the immune system of the individual. The previously mentioned shows that the combination between the use of tobacco and having HIV can increase the risk of chronic lung disease ${ }^{[8,9]}$.

When the first antiretroviral therapy (ART) program was established in Africa in the early years of the 21st century, there were a lot of skepticism ${ }^{[10]}$. However, over the years, advances in ART have been able to extend the life of patients with HIV, for those reasons the HIV infection thus became a treatable chronic condition ${ }^{[1,11-13]}$. A fact that proves the above is that ART increased the average of life expectancy in HIV infected persons from 10.5 years in 1996 to 22.5 years in $2005^{[1,11]}$. However, it is important to note that, the side effects of these therapies can cause increased risk of developing many chronic conditions and infectious in these patients. If we add tobacco use, which can affect the liver's ability to process drugs and worsen liver problems, the combination can be deadly ${ }^{[14,15]}$. Likewise, problems such as mouth sores or infections (thrush), herpes inside the mouth, tongue or lips, dental problems, gum and mouth cancer are related and may be exacerbated by the tobacco use in this population ${ }^{[5,16-18]}$.

To decrease the number of diagnoses of HIV infection among disproportionately affected populations, it is important to reducing HIV risk behaviors and increase the access to testing and care ${ }^{[3]}$. Given the difficulties and complications that we face when using tobacco and the presence of HIV, one of the best ways to prevent the virus spreading is to know that people are infected or not and take protective measures for themselves, avoiding opportunistic infections and limiting the spread of the virus. The HIV test will eliminate the uncertainty created by not knowing if they are HIV positive or negative. With the diagnosis, the person will be able to start more early existing retroviral treatments to improve their quality of life and increasing their survival. With this in mind, the main objective of this research is to provide an epidemiological profile of people who reported having an HIV test in their lifetime and smoke in Puerto Rico. Likewise, our secondary objectives are: 1) identify the existence of statistically significant differences between PHHT-S vs. PHHT-NS, and 2) determine the risk of having been in a risk situation for HIV infection among PHHT-S vs. PHHT-NS.

\section{Methods}

Through a cross-sectional study methodology the analysis of 2010 database of the Puerto Rico Behavioral Risk Factor Surveillance System (PRBRFSS) was performed with the Statistical Package for the Social Sciences (SPSS). The Behavioral Risk Factor Surveillance System (BRFSS) is a population based telephone survey funded by the Center for Disease Control and Prevention (CDC). The survey is conducted annually in all 50 states, the District of Columbia, Guam, Puerto Rico, and the US Virgin Islands. Annually more than 350,000 adults are interviewed for this reason; the BRFSS is 
considered the largest telephone health survey in the world. In Puerto Rico, this survey began in 1996 and is part of the Puerto Rico Department of Health.

The BRFSS contains information of non-institutionalized adults of 18 years and over, and includes more than 1,500 variables among which we can find socio-demographic, health conditions, tobacco and alcohol use, among others. Each year, after performing quality control measures, clearing and weighing the data, the PRBRFSS sends a copy of the database to the Puerto Rico Tobacco Control Program (PRTCP) to analyze everything related to tobacco use in the Island. This copy of the database does not contain personal information of the participants that allows us to identify them individually, for this reason they do not need ethical approvals for the analysis.

\section{Data analyses}

In the first part of the research, a univariate analysis was performed using frequency distributions for categorical variables and means and standard deviation for continuous variables. This analysis was performed to obtain a descriptive profile of people who have had an HIV test in their lifetime and smoke. In the second part of the research, smokers and non-smokers who have had an HIV test in their lifetime were compared to identify statistically significant differences. This comparison was performed through a bivariate analysis using Chi-square tests. Finally, a logistic regression controlling by sex, age, marital status, educational level and annual income was performed to determine the risk of having been in a risk situation for HIV infection among PHHT-S vs. PHHT-NS (Odds Ratio and 95\% confidence intervals).

\section{Results}

\section{People who have had HIV test in their lifetime and smoke (PHHT-S)}

It was found for 2010, that among the $43.1 \%(1,009,587)$ of the Puerto Rico residents of 18 years and over who have had an HIV test in their lifetime, $16.6 \%(167,242)$ reported being smokers (see Table 1$)$. In terms of sex, for PHHT-S, more than half (56.2\%) were males (Table 2). The mean age for PHHT-S was 37 years (SD 10.5) and the highest proportion of people was in the group of 25-34 years (36.8\%), followed by the groups of 35-44 years (29.7\%) and 45-57 years (17.2\%) (see Table 2). At the same time, other groups with the highest proportion of PHHT-S were people who graduated of high school (29.1\%), people with an annual income less than $\$ 15,000$ (48.7\%), salaried employees (34.8\%), and people who reported 'never been married' (43.6\%) (see Table 2).

Table 1. Puerto Rico residents with 18 year and over who have had an HIV test in their life time by smoking status

\begin{tabular}{|c|c|c|c|c|c|c|c|}
\hline & \multirow{2}{*}{\multicolumn{2}{|c|}{ Total }} & \multicolumn{4}{|c|}{ Smoking Status } & \multirow{3}{*}{$p$ value * } \\
\hline & & & Yes & & No & & \\
\hline & $\mathbf{n}$ & $\%$ & $\mathbf{n}$ & $\%$ & $\mathbf{n}$ & $\%$ & \\
\hline \multicolumn{8}{|c|}{ HIV test } \\
\hline Yes & $1,009,587$ & 43.1 & 167,242 & 16.6 & 842,345 & 83.4 & \multirow{2}{*}{$<0.001$} \\
\hline No & $1,332,067$ & 56.9 & 140,966 & 10.6 & $1,191,101$ & 89.4 & \\
\hline
\end{tabular}

* Pearson Chi-Square Tests

Almost Eighty-seven percent (86.6\%) of PHHT-S reported having health coverage. In terms of general health, 33.2\% of PHHT-S reported a good general health and $48.8 \%$ reported being satisfied with their life. Notwithstanding the above, $19.2 \%$ of PHHT-S reported having some limitation in their daily activities due to health problems. Finally, more than forty percent (41.1\%) of PHHT-S reported being binge drinkers and 13.6\% reported having been in any of the following situations of risk for HIV: use of intravenous drugs in the past year, treated for a sexually transmitted or venereal disease in the past year, given or received money or drugs in exchange for sex in the past year, and had anal sex without a condom in the past year. 
Table 2. Socio demographics data by PHHT-NS and PHHT-S

\begin{tabular}{|c|c|c|c|c|c|}
\hline \multirow{2}{*}{ Variables } & \multicolumn{2}{|l|}{ PHHT-S } & \multicolumn{2}{|c|}{ PHHT-NS } & \multirow[t]{2}{*}{$p$ value * } \\
\hline & $\mathbf{n}$ & $\%$ & $\mathbf{n}$ & $\%$ & \\
\hline Sex & 167,242 & & 842,345 & & \\
\hline Male & 93,999 & 56.2 & 342,614 & 40.7 & \multirow{2}{*}{$<0.001$} \\
\hline Female & 73,243 & 43.8 & 499,731 & 59.3 & \\
\hline Age & 167,242 & & 842,345 & & \multirow{6}{*}{$<0.001$} \\
\hline $18-24$ & 17,289 & 10.3 & 117,816 & 14.0 & \\
\hline $25-34$ & 61,529 & 36.8 & 223,351 & 26.5 & \\
\hline $35-44$ & 49,605 & 29.7 & 257,410 & 30.6 & \\
\hline $45-54$ & 28,771 & 17.2 & 157,996 & 18.8 & \\
\hline $55-64$ & 10,048 & 6.0 & 85,772 & 10.2 & \\
\hline Marital status & 167,243 & & 837,103 & & \multirow{7}{*}{$<0.001$} \\
\hline Married & 40,718 & 24.3 & 466,200 & 55.7 & \\
\hline Divorced & 27,687 & 16.6 & 88,848 & 10.6 & \\
\hline Widowed & 4,047 & 2.4 & 14,860 & 1.8 & \\
\hline Separated & 5,918 & 3.5 & 26,634 & 3.2 & \\
\hline Never married & 72,930 & 43.6 & 145,740 & 17.4 & \\
\hline A member of an unmarried couple & 15,943 & 9.5 & 94,821 & 11.3 & \\
\hline Education & 167,241 & & 841,681 & & \multirow{5}{*}{$<0.001$} \\
\hline Did not graduate High School & 32,567 & 19.5 & 73,649 & 8.8 & \\
\hline Graduated of High School & 48,740 & 29.1 & 160,115 & 19.0 & \\
\hline Attended College or Technical School & 46,101 & 27.6 & 258,335 & 30.7 & \\
\hline $\begin{array}{l}\text { Graduated from college or technical } \\
\text { school }\end{array}$ & 39,833 & 23.8 & 349,582 & 41.5 & \\
\hline Income & 123,516 & & 677,947 & & \multirow{6}{*}{$<0.001$} \\
\hline Less than $\$ 15,000$ & 60,187 & 48.7 & 216,260 & 31.9 & \\
\hline$\$ 15,000-\$ 24,999$ & 39,776 & 32.2 & 204,127 & 30.1 & \\
\hline \$ 25,000 - \$ 34,999 & 11,866 & 9.6 & 103,724 & 15.3 & \\
\hline \$ 35,000 - \$ 49,999 & 7,146 & 5.8 & 71,376 & 10.5 & \\
\hline$\$ 50,000$ or more & 4,541 & 3.7 & 82,460 & 12.2 & \\
\hline Employment status & 165,873 & & 835,229 & & \multirow{9}{*}{$<0.001$} \\
\hline Employed for wages & 57,760 & 34.8 & 390,237 & 46.7 & \\
\hline Self-employed & 14,092 & 8.5 & 99,793 & 11.9 & \\
\hline Out of work for more than 1 year & 24,355 & 14.7 & 42,803 & 5.1 & \\
\hline Out of work for less than 1 year & 12,853 & 7.7 & 35,935 & 4.3 & \\
\hline A homemaker & 19,957 & 12.0 & 142,736 & 17.1 & \\
\hline A student & 15,069 & 9.1 & 51,790 & 6.2 & \\
\hline Retired & 2,807 & 1.7 & 33,904 & 4.1 & \\
\hline Unable to work & 18,980 & 11.4 & 38,031 & 4.6 & \\
\hline
\end{tabular}

Note. PHHT-S, People who having an HIV test ever in a life and smoke; PHHT-NS People who having an HIV test ever in a life and do not smoke

* Pearson Chi-Square Tests

People who have had an HIV test in their lifetime and smoke (PHHT-S) vs. People who have had an HIV test in their lifetime and do not smoke (PHHT-NS)

When both groups were compared, more than half of PHHT-S were males (56.2\%) while in PHHT-NS more than half were female $(59.3 \%)(p<0.001)$ (see Table 2). The mean years for PHHT-S were 37 years (SD 10.5) and for PHHT-NS 
were 38 years (SD 11.7) $(p<0.001)$. The age group with a higher proportion in PHHT-S was $25-34$ years $(36.8 \%)$ and in PHHT-NS was the group of 35-44 years $(30.6 \%)(p<0.001)$ (see Table 2). Close to thirty percent of PHHT-S reported having graduated from high school (29.1\%), but more than thirty percent of PHHT-NS reported having some years in college or technical school (30.75) $(p<0.001)$ (see Table 2). In terms of annual income, in both groups, a higher proportion of people reported an annual income less than $\$ 15,000$ (PHHT-S=48.7\% vs. PHHT-NS=31.9\%) ( $p<0.001$ ) (see Table 2). When the data were analyzed by employment status, the PHHT-S had lower proportion of salaried employees (34.8\%) vs. PHHT-NS (46.7\%) $(p<0.001)$ (see Table 2). Less than half of the PHHT-S (43.6\%) reported never being married while more than half of the PHHT-NS (55.7\%) reported being married $(p<0.001)$ (see Table 2).

PHHT-S have lower proportion of people with health coverage (86.8\%) than PHHT-NS (92.1\%) $(p<0.001)$. More than thirty percent in both groups reported a good general health (PHHT-S $=33.2 \%$ vs. PHHT-NS $=33.7 \%)(p<0.001)$ but $48.8 \%$ of PHHT-S reported being satisfied with their life and $49.5 \%$ of PHHT-NS reported being very satisfied with their life $(p<0.001)$. Also higher proportion of PHHT-S (19.2\%) than PHHT-NS (10.6\%) reported having some limitation in their daily activities due to health problems $(p<0.001)$. Similarly, higher proportion of PHHT-S (41.1\%) than PHHT-NS (11.6\%) reported being binge drinkers ( $p<0.001)$, and higher proportion of PHHT-S (13.6\%) than PHHT-NS (5.5\%) $(p<0.001)$ reported having been in any of the following risk situation for HIV: use of intravenous drugs in the past year, treated for a sexually transmitted or venereal disease in the past year, given or received money or drugs in exchange for sex in the past year, and had anal sex without a condom in the past year. Finally, a logistic regression was performed to determine the risk of having been in a risk situation for HIV infection among PHHT-S vs. PHHT-NS. Controlling for the following categorical variables: sex, age, marital status, education level, and annual income, the PHHT-S are 2.24 (95\% CI: 2.19, 2.29) times more likely to be involved in a risk situation for HIV in comparison with the PHHT-NS.

\section{Discussion}

This study is the first to establish a comparison between PHHT-S and PHHT-NS using a population database in Puerto Rico. In addition, we seldom see papers, which are methodologically based on a cohort, which is $100 \%$ Hispanic or Latino. In terms of minorities, Blacks and Latinos in United States continue to be disproportionately affected, despite overall advances in HIV testing and care ${ }^{[19]}$. The estimate lifetime risk for HIV diagnosis in Latinos was approximately three times that for whites and, among racial/ethnic populations, was greater than all populations except Blacks ${ }^{[3]}$. For this reason, it is important to increase the rates of HIV testing among groups not traditionally perceived as being at risk ${ }^{[20]}$ in the Latino population, and one of these groups are the smokers.

HIV/AIDS and tobacco use represent the only two major causes of death globally that continues growing ${ }^{[5]}$. Tobacco use is a leading cause of morbidity and mortality in people without HIV and is highly prevalent in the HIV positive population ${ }^{[21]}$. At the same time, tobacco use has been found to be independently associated with mortality in HIV positive smokers ${ }^{[22]}$. Likewise, more than $85 \%$ of the people with HIV in the U.S. have a lifetime history of smoking ${ }^{[22]}$, but there is no convincing scientific evidence that directly links the tobacco use with the acquisition of HIV virus. Despite the above, the findings of this study present statistically significant data to support the existence of differences between PHHT-S and PHHT-NS especially in the area of risk behaviors related to HIV. According to the result of this study, PHHT-S are 2.24 times more likely to engage in some risky behavior that can lead them to be infected by HIV than PHHT-NS.

\section{Conclusion}

The HIV test is important to determine the HIV status in the population and prevent the spread of the infection. At the same time, an early diagnosis of the infection is important to ensure that people are promptly referred for evaluation, offered treatment and counselling ${ }^{[23,24]}$. It is important from a human rights perspective to be able to access quality HIV testing 
and counselling services that are clearly linked to effective prevention, treatment and care programs ${ }^{[25]}$. For these reasons, and based on the results of this study, it is important that Tobacco Control Programs begin to establish collaboration with HIV programs to develop, test and implement new strategies to promote a greater number of people who smoke get tested for HIV and to influence public policy and systems change.

\section{Strengths and limitation}

The main strength of this study is that is the first epidemiological study in Puerto Rico that describes and compares the PHHT-S and PHHT-NS using a population database that is representative of the Puerto Rico's adult population (ages 18 and older). BRFSS data are weighted for the probability of selection of a telephone number, the number of adults in a household, and the number of phones in a household, and is adjusted to reflect the demographic distribution of Puerto Rico's adult population (ages 18 and older). One limitation of the database is that cellular phones are not included as part of the regular BRFSS sample in 2010. This is an important issue because the federal communication commission estimated that $26.4 \%$ of households in Puerto Rico do not have a telephone service. Finally, the database collection is limited to a single time point (cross-sectional design). As a result, study findings can only describe the 2010 cohort and cannot assess changes over time.

\section{Competing interests}

There are no conflicts of interest to declare.

\section{Acknowledgement}

The authors wish to acknowledge Ruby A. Serrano Rodríguez, DrPH, Director of the Puerto Rico Behavioral Risk Surveillance System providing the data used for analysis in this study.

\section{References}

[1] Atum R, Bataringaya J. Building a durable response to HIV/AIDS: implications for health systems. J Acquir Immune Defic Syndr. 2011; 57(2): S91-S95. PMid:21857305 http://dx.doi.org/10.1097/QAI.0b013e3182218441

[2] Young SD, Bendavid E. The relationship between HIV testing, stigma, and health service usage. AIDS Care. 2010; 22 (3): 373-380. PMid:20390518 http://dx.doi.org/10.1080/09540120903193666

[3] Adih WK, Hu X, Campsmith ML, et al. Estimated lifetime risk for diagnosis of HIV infection among Hispanics/Latinos - 37 States and Puerto Rico, 2007. CDC MMWR. 2010; 59(40): 1297-1301.

[4] Centers for Disease Control and Prevention. Behavioral Risk Factor Surveillance System Data sets. 2010 annual survey data. Available from: http://www.cdc.gov/brfss/technical_infodata/surveydata/2010.htm. Last accessed: January 2012.

[5] Furber AS, Maheswaran R, Newell JN, et al. Is smoking tobacco an independent risk factor for HIV infection and progression to AIDS? A systemic review. Sex Transm Infect. 2007; 83: 41-46. PMid:16923740 http://dx.doi.org/10.1136/sti.2005.019505

[6] Arcavi L, Benowitz NL. Cigarette smoking and infection. Arch Intern Med. 2004; 164: 2206-2216. PMid:15534156 http://dx.doi.org/10.1001/archinte.164.20.2206

[7] Wolf R, Freedman D, Cigarette smoking, sexually transmitted diseases, and HIV/AIDS. Int J Dermatol. 2000 ; 39 : 1-9. PMid:10651955 http://dx.doi.org/10.1046/j.1365-4362.2000.00721.x

[8] Marshall MM, McCormack, Kirk GD. Effect of cigarette smoking on HIV acquisition, progression, and mortality. AIDS Educ Prev. 2009; 21(3): 28-29. PMid:19537952 http://dx.doi.org/10.1521/aeap.2009.21.3_supp.28

[9] Weeb MS, Vanable PA, Carey MP. Cigarette smoking among HIV+ Men and Women: Examining health, substance use, and psychosocial correlate across the smoking spectrum. J Behav Med. 2007; 30(5): 371-383. PMid:17570050 http://dx.doi.org/10.1007/s10865-007-9112-9

[10] Montague B, Vuylsteke B, Buvé A. Sustentability of programs to reach high risk and marginalized populations living with HIV in resource limited settings: implications for HIV treatment and prevention. BMC Public Health. 2011; 11: 701. PMid:21917178 http://dx.doi.org/10.1186/1471-2458-11-701 
[11] Harrison KM, Song R, Zhang X. Life expectancy after HIV diagnosis bases on national HIV surveillance data from 25 states, United States. J acquir Immune Syndr. 2010; 53(1): 124-130. PMid:19730109 http://dx.doi.org/10.1097/QAI.0b013e3181b563e7

[12] Atun R, Gurol-Urganci I, McKee M. Health systems and increased longevity in people with HIV and AIDS. BMJ. 2009; 338: b2165. PMid:19541695 http://dx.doi.org/10.1136/bmj.b2165

[13] Mothi SN, Karpagam S, Swamy VHT, et al. Pediatric HIV - trends \& challenges. Indian J Med Res. 2011; 134 : $912-919$. PMid:22310823 http://dx.doi.org/10.4103/0971-5916.92636

[14] Goldberg D, Weber KM, Orsini J, et al. Smoking Cessation Among Women with and at Risk for HIV: Are They Quitting? Med. 2010; 25(1): 39-44.

[15] Duval X, Baron G, Garelik D, et al. Living with HIV, antiretroviral treatment experience and tobacco smoking: results from a multisite cross-sectional study. Antivir Ther. 2008; 13(3): 389-397. PMid:18572752

[16] Feldman JG, Minkoff H, Schneider MF, et al. Association of Cigarette Smoking With HIV Prognosis Among Women in the HAART era: a Report From the Women’s Interagency HIV Study. Am J Public Health. 2006; 96(6):1060-1065. PMid:16670229 http://dx.doi.org/10.2105/AJPH.2005.062745

[17] Hoffman AC, Starks VL, Gritz ER. The Impact of Cigarette Smoking on HIVAIDS Urgent Need for Research and Cessation Treatment. AIDS Educ Prev. 2009; 21(3): 1-2. PMid:19537949 http://dx.doi.org/10.1521/aeap.2009.21.3_supp.1

[18] Burkhalter JE, Springer CM, Chhabra R, Jamie S, et all. Tobacco use and readiness to quit smoking in low-income HIV-infected persons. Nicotine \& Tobacco Research. 2005; 7(4): 511-522. PMid:16085522 http://dx.doi.org/10.1080/14622200500186064

[19] Buchbinder S, HIV epidemiology and breakthroughs in prevention 30 years into the AIDS epidemic. Top Antivir Med. 2011; 19(2): 38-46. PMid:21868821

[20] Ostermann J, Kumar V, Pence BW, et al. Trends in HIV testing and differences between planned and actual testing in the United States, 2000-2005. Arch Intern Med. 2007; 167(19): 2128-2135. PMid:17954809 http://dx.doi.org/10.1001/archinte.167.19.2128

[21] Crothers K, Goulet J, Rodriguez-Barradas MC, et al. Impact of cigarette smoking on mortality in HIV-positive and HIV-negative veterans. AIDS Education and Prevention. 2009; 21(A): 40-53.

[22] Nahvi S, Cooperman N. Review: The need for smoking cessation among HIV-positive smokers. AIDS Educ Prev. 2009; 21(3): 14-27. PMid:19537951 http://dx.doi.org/10.1521/aeap.2009.21.3_supp.14

[23] Centers for Disease Control and Prevention. HIV infection: detection, counseling, and referral. Available from: http://www.cdc.gov/std/treatment/2010/hiv.htm. Last accessed: June 2012.

[24] Kaiser Family Foundatio’s. Fact Sheet: HIV Testing in the United States 2011. Available from: http://www.kff.org/hivaids/upload/6094-11.pdf. Last accessed: May 2012.

[25] World Health Organization. Improving HIV testing and counseling services. Available from: http://whqlibdoc.who.int/hq/2011/WHO_HIV_11.01_eng.pdf. Last accessed: July 2012. 